\title{
Ectopic Pregnancy: Epidemiological, Clinical, Therapeutical, Anatomopathological Aspects and Prognosis at the Department of Obstetrics and Gynecology of the Teaching Hospital Souro Sanou of Bobo-Dioulasso: About 79 Cases and Literature Review
}

\author{
Bambara Moussa1, Togbe Alihonou Eric Serge1, Lankoande David1, Dembele Adama1, \\ Ouedraogo Issa ${ }^{2}$
}

\footnotetext{
${ }^{1}$ Head Department of Obstetrics and Gynaecology, Teaching Hospital Sourô Sanou of Bobo-Dioulasso, Bobo-Dioulasso, Burkina Faso ${ }^{2}$ Gynaecologist Obstetrician, UHO, Ouayigouya, Burkina Faso

Email: mousbambara@yahoo.fr, togbeserges@yahoo.fr, lankoande_david@yahoo.fr,dembadama@hotmail.com, oued_issa2002@yahoo.fr
}

\begin{abstract}
How to cite this paper: Moussa, B., Serge, T.A.E., David, L., Adama, D. and Issa, O. (2022) Anatomopathological Aspects and Prognosis at the Department of Obstetrics and Gynecology of the Teaching Hospital Souro Sanou of Bobo-Dioulasso: About 79 Cases and Literature Review. Open Journal of Obstetrics and Gynecology, 12, 1-10. https://doi.org/10.4236/ojog.2022.121001
\end{abstract}

Received: October 25, 2021

Accepted: January 10, 2022

Published: January 13, 2022

Copyright $\odot 2022$ by author(s) and Scientific Research Publishing Inc. This work is licensed under the Creative Commons Attribution International License (CC BY 4.0).

http://creativecommons.org/licenses/by/4.0/ (c) (i) Open Access

\begin{abstract}
Objective: To study the epidemiological, clinical, therapeutical, anatomopathological aspects and prognosis of the ectopic pregnancy. Methodology: It was a transversal and descriptive study from January $1^{\text {st }}$ to December $31^{\text {st }}$ 2018 at the department of obstetrics and gynecology of the Teaching Hospital Sourô Sanou of Bobo-Dioulasso. Results: During the study period, we registered 4706 deliveries with 1272 cases of cesareans and 79 cases of ectopic pregnancy with a frequency of 1 ectopic pregnancy for 60 deliveries and 6 ectopic pregnancies for 100 caesareans. The average age of the patients in our study was 28.66 years old ( $19-45$ years) and the average parity of 1.96 [0 - 6]. Married women represented $83.54 \%$ of the workforce. The risk factors were dominated by sexual transmitted diseases (25.31\%) and abortions (20.25\%). Clinical signs were dominated by pelvic pain (100\% of cases), metrorrhagea (86.5\% of cases) and amenorrhea (64.6\% of cases). Culdocentesis brought lysed incoagulable blood in $83.7 \%$ cases. The immunological pregnancy test was positive in $100 \%$ of cases. Plasma beta dosage was carried out in 2 cases. Salpingectomy was performed in $97.4 \%$ cases. The site of the ectopic pregnancy was interstitial in $11.3 \%$ cases, isthmic in $8.86 \%$ cases, infundibular in $11.3 \%$ cases, ampullar in $77.22 \%$ cases. On the anatomopathological level, we noted an acute salpingitis in $23.38 \%$ cases and a chronic salpingitis in $44.94 \%$
\end{abstract}


cases. Postoperative were simple in $97.7 \%$ of cases and we deplored one case maternal death. Conclusion: Ectopic pregnancy is a surgical emergency of the first trimester pregnancy. The delay in diagnosis is common in our context, with as consequence a mutilated treatment. The etiological factors are dominated by the chronic salpingitis and the acute salpingitis. The prevention is based on combatting genital infections, promoting contraceptive methods and a good post abortion care.

\section{Keywords}

Ectopic Pregnancy, Surgical Emergency, Salpingectomy, Prognosis

\section{Introduction}

Ectopic pregnancy is a surgical emergency of the first trimester pregnancy. It is the first cause of maternal deaths of the first trimester pregnancy in France [1]. Its frequency is increasing since the two last decades because of the sexually transmitted diseases, tubal surgery and the medically assisted procreation [2]. The early diagnosis in the developed countries allows a conservative treatment because of the level of the patient's education with an adequate technical platform (vaginal ultrasound, quantitative $\beta$ hCG plasma assay, coelio surgery) [3]. The situation is not the same in developing countries where the diagnosis is late because of the poor technical platforms with a radical surgical treatment [4] [5] [6] [7]. In other word, the people don't have a good level of education to understand that a vaginal bleeding in the first trimester pregnancy could be a serious health problem in developing countries. Women generally come at a late stage with a ruptured ectopic pregnancy. We propose through a cross-sectional and descriptive study to learn the epidemiological, clinical, therapeutical and anatomopathological aspects of this affection at the department of obstetrics and gynecology of the Teaching Hospital Sourô Sanou of Bobo-Dioulasso.

\section{Methods}

It was a descriptive and transversal study on 79 cases of ectopic pregnancies observed at the department of obstetrics and gynecology of the Teaching Hospital Sourô Sanou of Bobo-Dioulasso, conducted on a period of 12 months, from January $1^{\text {st }}$ to December $31^{\text {st }}, 2018$.

Was included any patient admitted in our department presenting clinical and paraclinical signs of ectopic pregnancy and being taken in charge.

Was not included any patient that does not show any clinical and paraclinical signs of ectopic pregnancy. We deed a survey sheet for each patient. The parameters studied were the sociodemographic characteristics, the obstetric gynecological history, clinical and paraclinical aspects, maternal care and prognosis. The data were collected from a survey form, clinical files, operating procedures and anatomopathological reports. Data entry and analysis were carried out by 
softwares Word and Epi-Info 6.0.

\section{Results}

\subsection{Epidemiology}

- Frequency

From January $1^{\text {st }}$ to December $31^{\text {st }} 2018$, we registered 4706 deliveries and 1272 from caesarean and 79 cases of ectopic pregnancies with a frequency of one ectopic pregnancy for 60 deliveries and 6 ectopic pregnancies for 100 cesareans.

- Sociodemographic characteristics

They are summarized up in Tables 1-4.

Table 1. Sociodemographic characteristics.

\begin{tabular}{|c|c|c|}
\hline Parameters & Number & $\%$ \\
\hline \multicolumn{3}{|l|}{ Age (years) } \\
\hline $15-19$ & 1 & 1.27 \\
\hline $20-29$ & 43 & 54.50 \\
\hline $30-39$ & 33 & 41.80 \\
\hline$\geq 40$ & 2 & 2.60 \\
\hline \multicolumn{3}{|l|}{ Parity } \\
\hline Nullipara & 22 & 27.85 \\
\hline Primipara & 20 & 25.31 \\
\hline Paucipara & 11 & 13.93 \\
\hline Multipara & 0 & 0 \\
\hline \multicolumn{3}{|l|}{ Profession } \\
\hline Housewife & 61 & 77 \\
\hline Trader & 16 & 32 \\
\hline Pupil/Student & 4 & 5 \\
\hline \multicolumn{3}{|c|}{ Statut matrimonial } \\
\hline Married & 66 & 77 \\
\hline Divorced & 1 & 1.27 \\
\hline Single & 12 & 15.9 \\
\hline \multicolumn{3}{|l|}{ Origin } \\
\hline Rural Area & 53.9 & 68.35 \\
\hline Urban Area & 25 & 31.65 \\
\hline
\end{tabular}

Table 2. Gynecologic history.

\begin{tabular}{ccc}
\hline Gynecologic History & Number & $\%$ \\
\hline Spontaneous abortion & 15 & 18.99 \\
Avortement clandestin & 1 & 1.26 \\
Genital infection & 20 & 25.31 \\
Contraception & 12 & 15.19 \\
Pelvic Surgery & 2 & 2.53 \\
Ectopic pregnancy History & 4 & 5.06 \\
Any history & 3 & 3.8 \\
\hline
\end{tabular}


Table 3. Contraception history.

\begin{tabular}{ccc}
\hline Contraception method & Number & $\%$ \\
\hline IDU & 1 & 1.26 \\
Micropil & 6 & 7.59 \\
Injectable & 5 & 6.32 \\
\hline
\end{tabular}

Table 4. Clinical signs.

\begin{tabular}{ccc}
\hline Clinical signs & Effectif & $\%$ \\
\hline Late menstruation & 76 & 96.20 \\
Pelvic Pain & 79 & 100 \\
Metrorrhagea & 64 & 81.01 \\
Vertigo & 21 & 26.65 \\
Clinical Anemia & 25 & 31.65 \\
Shoc state & 11 & 13.92 \\
Umbilicus Cry & 55 & 68.35 \\
Sloping dullness of the flanks & 60 & 69,62 \\
Hypogastric defense & 60 & 69.62 \\
Latero uterine Mass & 40 & 50.63 \\
\hline
\end{tabular}

- Gynecologic History

- Contraception History

- Clinical and paraclinical aspects

1) Clinical signs

2) Paraclinical signs

-Dipstick pregnancy immunological test: the result was positive in $100 \%$ of cases.

-Pelvic ultrasound: it was carried out suprapubic in urgency with $65.82 \%$ of patients. The result showed an ectopic pregnancy, either an empty uterus associated to a latero uterine mass, or an empty uterus associated to a latero uterine mass and an effusion in Douglas sac cule or a hemoperitoneum associated to an empty uterus in a context of late menstruation.

-Quantitative $\beta$ hCG plasma assay was carried out in 2 cases because of its high price, and the result came back positive.

-The blood count carried out in 100\% of cases showed a severe anemia in 30\% of cases ( 3 to $6.9 \mathrm{~g} / \mathrm{dl})$, moderate in $20.25 \%$ of cases ( 7 à $9 \mathrm{~g} / \mathrm{dl})$, light in 35.44 cases $(9$ to $11 \mathrm{~g} / \mathrm{dl})$.

\subsection{Therapeutical Aspects}

The treatment of ectopic pregnancy in our series was a surgical treatment because of the late diagnosis.

We noticed a hemoperitoneum whose volume varied between 500 and $3000 \mathrm{cc}$ that we sucked.

The intervention was a salpingectomy after a laparotomy in 97 cases and 2 
cases of abdominal pregnancy extraction. During the procedure $45.57 \%$ of patients received a macromolecule infusion. After surgery, 29.2\% of patients received an Isogroup red blood cell transfusion of variable volume from 500 to $2000 \mathrm{cc}$

\subsection{Anatomopathological Aspects}

On a total of 77 salpingectomy surgery units analyzed, the results of the histological examination were the following: the presence of chorionic villi in $100 \%$ of cases, presence of embryo in $84.4 \%$ of cases. The anatomopathological examination of the tube showed a chronic salpingitis in $23.38 \%$ of cases. The tube was normal in $32.46 \%$ of cases.

\subsection{Maternal Prognosis}

Postoperative follow-ups were simple in 74 cases (94.94\%).

Postoperative follow-ups were complicated in 4 cases (5\%) because of anemia.

We noted 1 case of maternal death in a context of acute anemia decompensated in postoperative.

\section{Discussion}

\subsection{Limitations of the Study}

- chlamydia serology could not be performed in our patients because of its high cost and its unavailability at the Teaching Hospital Sourô Sanou;

- the history of abortion was difficult to admit by the patients;

- the inability to realize quantitative $\beta$ hCG plasma assay in many patients whose condition required monitoring because of its high cost;

- the inability to perform pelvic ultrasound in $44 \%$ of cases.

\subsection{Epidemiology}

The frequency noted in our series was $1.68 \%$ of deliveries. It is more than those reported by Dieme [8] at Dakar in 2011 and Balde [9] at Conakry in 20214 that were respectively $1.2 \%$ and $1.3 \%$. It is less that those reported by Agbeno [10] in Ghana and Kathpalia [11] in India that were respectively $1.8 \%$ and $2.46 \%$. In our context, this frequency seems to be linked to the risk factors as sexually transmitted diseases, genital infections, previous ectopic pregnancy and abortions [8].

According to Bouyer [2] and Lansac [12] the frequency of ectopic pregnancy in developed countries varies from 1 to $2 \%$ according to regions. Among the risk factors in industrialized countries, apart from the previous genital infections, we can cite plastic tubal surgery, in vitro fertilization and tobacco. The mechanism of action of tobacco can be hormonal or/and a direct toxicity of nicotine on the tubal mobility [2]. Jacob L [13] during a retrospective study in Germany on the risk factors of ectopic pregnancy, noted that role of age, endometriosis, pelvic surgery and psychiatric conditions.

The majority of surveys found that the ectopic pregnancy risk increases with 
age. The ectopic pregnancy concerns the young population and sexually active. The average age in our series was 28.66 years old. It's near to those reported in African series [4] [7] [8] [10]. The ectopic pregnancy is associated with a weak parity in our study and in most of the African series [5] [7] [8] [10]. From the results of many studies conducted in different continents, a meta-analysis showed a link between ectopic pregnancies and the main chlamydia infections. Chlamydia infection induces the risk of ectopic pregnancy [14].

\subsection{Diagnosis}

The pelvic pain was at the first plan in our study (100\% of cases). It is an almost constant sign reported by the majority of African authors because in Africa the most ectopic pregnancies are diagnosed at late stage [4] [7] [8] [9] [10].

Metrorrhagea is the second warning sign to recover with $81.59 \%$ of cases in our series. This was noticed by many authors with rates varying between $60 \%$ and $80 \%$ of cases [7] [8] [9] [10]. The late period was found in $96.20 \%$ of cases. The pelvic pain-metrorrhagea-delayed menstruation triad was found in the majority of cases in our series. She must evoke an ectopic pregnancy especially if there are sympathetic signs of pregnancy in a young woman in our context.

The dullness of the flanks, the state of shock and the cry of the navel are the late signs that translate the hemoperitoneum. In most African series the ectopic pregnancy diagnosis is made at a late stage [4] [5] [7] [8].

The vaginal ultrasound with high resolution has really improved the imaging of ectopic pregnancy. When it is coupled with the plasma $\beta$ hCG assay, it allows an early diagnosis of ectopic pregnancy [3] [15]. This development has significantly reduced the morbidity and mortality of this pathology in developed countries.

In our series, ultrasound was performed in $65.82 \%$ of cases with a contributive value in all the cases (empty uterus, latero uterine mass with most often abdominal effusion). In our context the immunological pregnancy test remains a valuable examination in the event of suspicion of ectopic pregnancy, mainly when after ultrasound the uterus is empty. In our study, it was carried out in $100 \%$ of cases.

The laparoscopy is now the gold standard for the diagnosis and treatment of ectopic pregnancy [3]. It was not available in our service during the period of the study (Figures 1-4).

\subsection{Therapeutical Aspects}

Laparotomy is widely used in the African series, the treatment of ectopic pregnancy [4] [5] [6] [8] [10] because of the late diagnosis and the extent of tubal damage. We used salpingectomy in $97.45 \%$ of cases in our study. The laparoscopy remains the standard treatment in developed countries [15] [16] [17].

For medical treatment, methotrexate is a treatment option for ectopic pregnancies with a rate of $\beta$ hCG not above $5000 \mathrm{UI} / \mathrm{L}$. Abstention is an option for those with a $\beta$ hCG level < 1500 UI/L [18] [19]. 


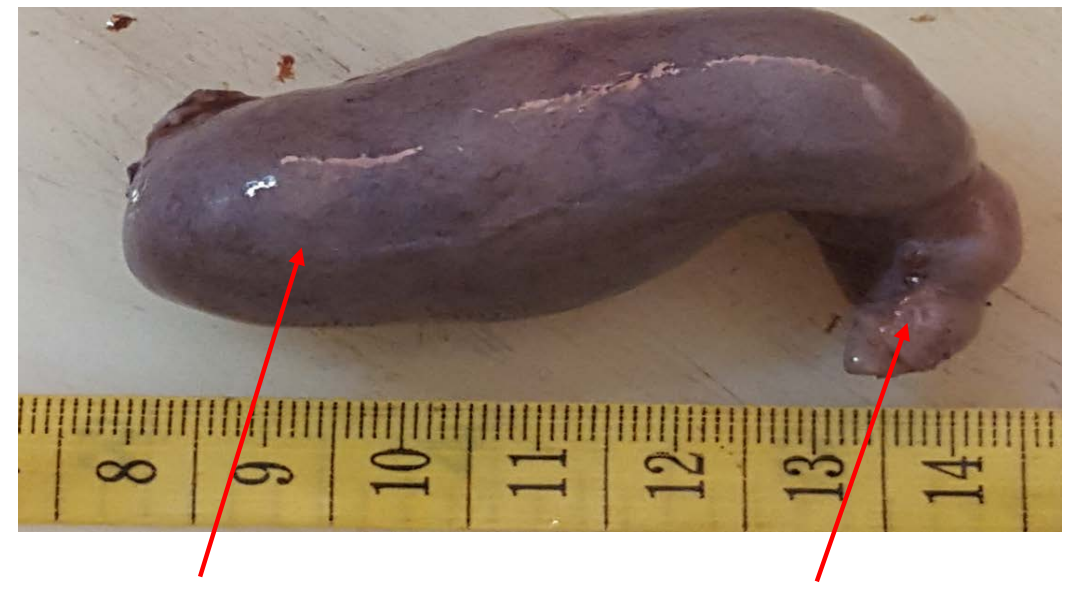

Ampullar portionlsthmicportion

Figure 1. Macroscopic aspect of left extrauterine pregnancy. The origin: Teaching Hospital Sourô Sanou.

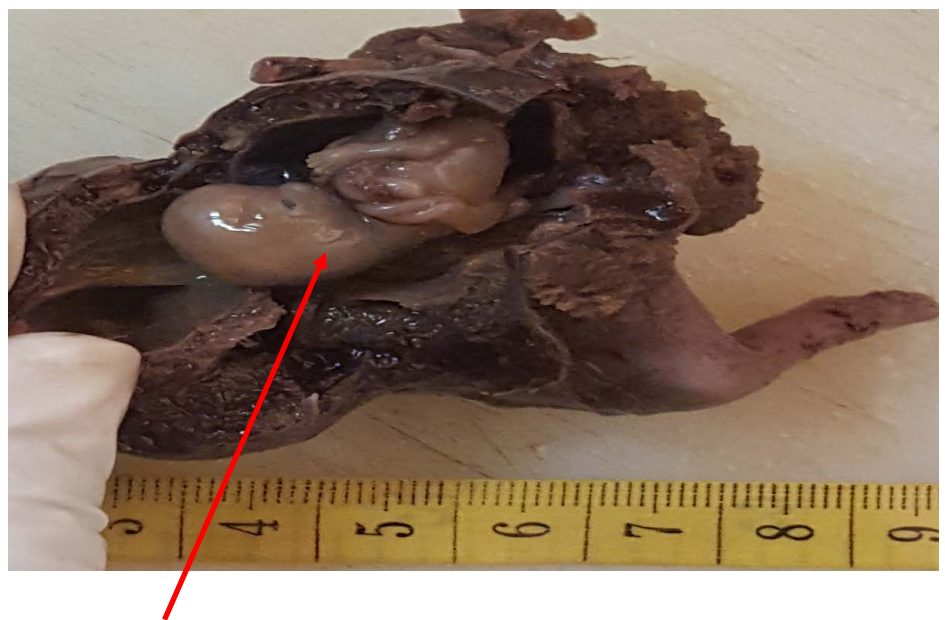

The Presence of an embryo $03 \mathrm{~cm}$ of craniocaudal length

Figure 2. Macroscopic aspect of ectopic pregnancy ruptured left tubal. The origin: Teaching Hospital Sourô Sanou.

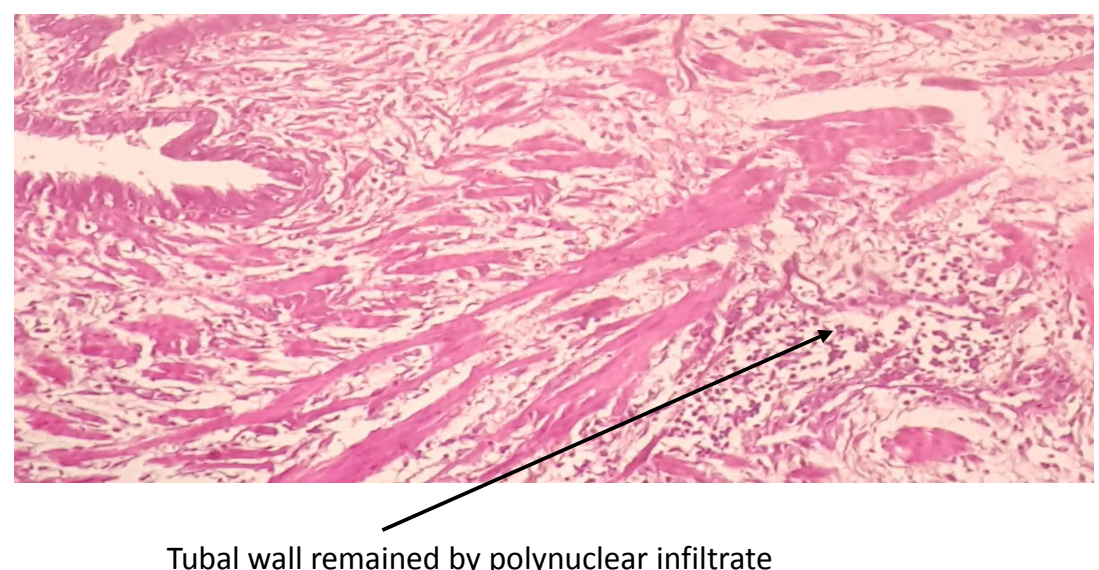

Figure 3. Microscopic aspect of acute salpingitis. The origin: Teaching Hospital Sourô Sanou. 


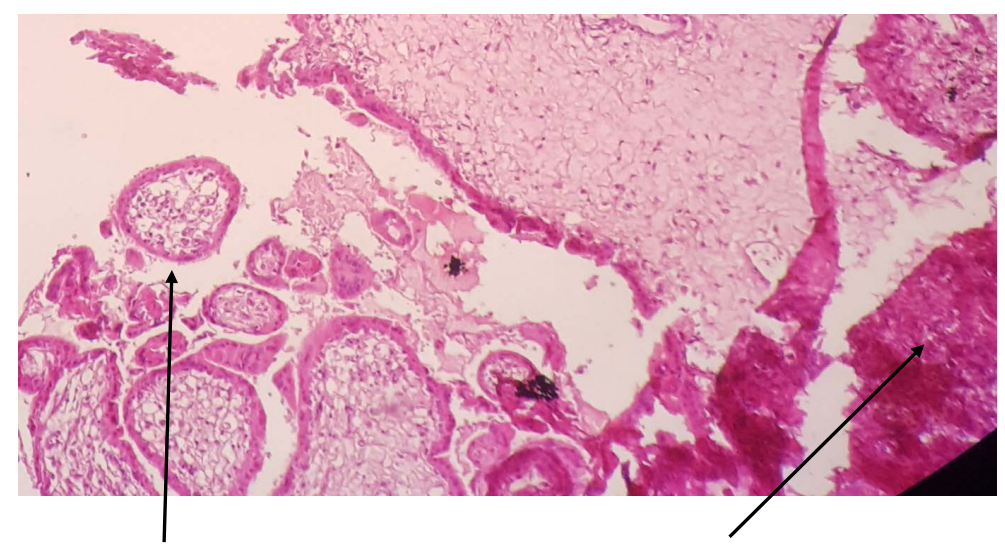

Chorionic villus Blood colt

Figure 4. Microscopic aspect of ruptured extrauterine pregnancy. The origin: Teaching Hospital Sourô Sanou.

\subsection{Anatomopathological Aspects}

In our series, chronic salpingitis was noted in $44.16 \%$ of cases and acute salpingitis in $23.38 \%$ of cases. The tube was normal in $32.85 \%$ of cases. Ahmed [20] in India reported cases of acute salpingitis in $34.78 \%$ and chronic salpingitis $53.91 \%$ of cases. Other pathologies such as molar pregnancy, bilharzia and endometriosis have been reported on histology [14] [21] [22]. This is to say the importance of the anatomopathological examination of any part of salpingectomy.

\subsection{Maternal Prognosis}

The post operatives were simple in $97.8 \%$ of cases in our series. We noted 4 cases of postoperative anemia corrected by transfusion with a favorable outcome. We noticed a maternal death ( $1.26 \%$ of cases). The mortality due to ectopic pregnancy is exceptional in developed countries.

\section{Conclusion}

The ectopic pregnancy in the African context constitutes a surgical emergency. Modern means of early diagnosis are not available most often (ultrasound, laparoscopy, $\beta \mathrm{hCG}$ ). The diagnosis is most often late with the consequence of mutilating surgery and a slowing down of subsequent fertility. Etiological factors are dominated by acute or chronic salpingitis. Prevention is based on raising public awareness for early consultation, the fight against sexually transmitted infections and induced abortions.

\section{Conflicts of Interest}

The authors declare no conflicts of interest regarding the publication of this paper.

\section{References}

[1] Naett, M. and Treisser, A. (1992) Extra Uterine Pregnancy: Etiology, Diagnosis, 
Evolution, Prognosis and Treatment. La Revue du Praticien, 42, 97-100.

[2] Bouyer, J. (2003) Epidemiology of Ectopic Pregnancy: Incidence, Risk Factors and Outcomes. Journal de gynecologie, obstetrique et biologie de la reproduction, 32, S8-S17.

[3] Ardaens, Y., Guérin, B., Perrot, N. and Legoeff, F. (2003) Contribution of Ultrasound in the Diagnosis of Extra Uterine Pregnancy. Journal de gynecologie, obstetrique et biologie de la reproduction, 32, 3S28-3S38.

[4] Sy, T., Diallo, Y., Touré, A., Diallo, F.B., Balde, A.A., Hyjazi, Y. and Diallo, M.S. (2009) Management of Extra Uterine Pregnancy in Conakry (Guinée). Medecine Tropicale, 69, 565-568.

[5] Dohbit, J.S., Foumane, P., Kapohem, D., Mboudou, T., Doumbe, M. and Doha, S. (2010) Ectopic Pregnancy at the Regional Hospital Center of Bafoussam: Epidemiological, Clinical and Therapeutical Aspects. Clinics in Mother and Child Health, 7, 1189-1193. https://doi.org/10.4303/cmch/C101977

[6] Diarra, L., Samaké, A., Konaté, M., Keita, M., Diallo, M., Traore, S.O., Maiga, M., Traore, O. and Traore, D. (2020) Late Diagnosis of Ruptured Extra Uterine Pregnancy. Health Sciences and Disease, 21, 131-134. www.hsd-fmsb.org

[7] Mbongo, J.A., Mawandza, P., Mpika, G.B., Itoua, C. and Iloki, L.H. (2019) Management of Ectopic Pregnancy at the Brazzaville Hospital and University Center. Open Journal of Obstetrics and Gynecology, 9, 1050-1057.

https://doi.org/10.4236/ojog.2019.97102

http://www.scirp.org/journal/ojog

[8] Dieme, E., Faye Dieme, M.E., Kane, R., Sall, I., Ndiaye, A.R., Ndiaye, R., Diouf, M., Fall, O., Sow, A., Ogougbémy, M. and Diouf, M.B. (2013) Extra Uterine Pregnancy at the Principal Hospital of Dakar: Diagnostically and Therapeutically Characteristics. Journal of African Society of Gynecologie and Obstetrique, 14, 27-32.

[9] Balde, I.S., Diallo, F.B., Conte, I., Diallo, M.H., Sylla, I., Diallo, B.S., et al. (2014) Extra Uterine Pregnancy in the Obstetrics and Gynecology Service at the Teaching Hospital Ignace-Deen of Conakry: Epidemiological, Sociodemographic, Therapeutical Aspects and Prognosis. Médecine et Santé Tropicales, 24, 297-300. https://doi.org/10.1684/mst.2014.0366

[10] Agbeno, E.K., Ofori1, A.A., Osarfo, J., Samuel, D., Adu, J.A., Amoah, S.K. and Azanu, W.K. (2020) Extrauterine Pregnancy: A Nine-Year Review of Incidence, Seasonality and Management at a Tertiary Hospital in Southern Ghana. Open Journal of Obstetrics and Gynecology, 10, 264-274. https://doi.org/10.4236/ojog.2020.1020023 https://www.scirp.org/journal/ojog

[11] Kathpalia, B.S.K., Arora, C.D., Sandhu, N. and Sinha, P. (2016) Ectopic Pregnancy: Review of 80 Cases. Medical Journal Armed Forces India, 804, 172-176. https://doi.org/10.1016/j.mjafi.2016.11.004

[12] Lansac, J., Lecompte, P. and Marret, H. (2007) Collection for the Practician. In: SIMEP, Gynecology, Vol. 574, 7th Edition, Masson, Paris, 12-23.

[13] Jacob, L., Kalder, M. and Kostev, K. (2017) Risk Factors for Ectopic Pregnancy in Germany: A Retrospective Study of 100,197 Patients. GMS German Medical Science, 15, Article No. Doc19. https://doi.org/10.3205/000260

[14] Xia, Q., Wang, T., Xian, J., Song, J., Qiao, Y., Mu, Z., Liu, H. and Sun, Z. (2020) Relation of Chlamydia Relation of Chlamydia Trachomatis Infections to Ectopic Pregnancy. A Meta-Analysis and Systematic Review. Medicine, 99, Article ID: e18489. https://doi.org/10.1097/MD.0000000000018489 
[15] Gervaise, A. and Fernandez, H. (2010) Diagnosis and Therapeutical Treatment of Ectopic Pregnancy. Journal de Gynécologie Obstétrique et Biologie de la Reproduction, 39, F17-F24. https://doi.org/10.1016/j.jgyn.2010.02.013

[16] Frey, C. and Poucelet, C. (2011) Extra Uterine Pregnancy Treatment. Gynécologie Obstétrique \& Fertilité, 39, 640-643. https://doi.org/10.1016/j.gyobfe.2011.09.006

[17] Wattiez, A., Waters, N. and Rodriguez, B. (2007) Extra Uterine Pregnancy: For the Conservative and Surgical Treatment. Gynécologie Obstétrique \& Fertilité, 35, 70-73. https://doi.org/10.1016/j.gyobfe.2006.12.003

[18] Lesavre, M., Curinier, S., Capmas, P., Rabischong, B. and Fernandez, H. (2015) Méthotrexate Use in the Tubal Extra Uterine Pregnancy. Journal de Gynécologie Obstétrique et Biologie de la Reproduction, 44, 212-219.

https://doi.org/10.1016/j.jgyn.2014.12.013

[19] Canis, M., Savary, D., Pouly, J.L.A. and Wattiez, M.G. (2003) Ectopic Pregnancy: Criteria to Decide between Medical and Conservative Surgical Treatment? Journal de Gynécologie Obstétrique et Biologie de la Reproduction, 32, S54-S63.

[20] Ahmed, M.I. and Begum, Z. (2018) A Study on Histopathological Findings in Ectopic Tubal Pregnancies and Evaluation of Associated Risk Factors. Indian Journal of Pathology: Research and Practice, 7, 928-933. https://doi.org/10.21088/ijprp.2278.148X.7818.8

[21] Farrukh, A., Attia, M. and Furniss, H. (2007) Tubal Hydatidiform Mole: An Unexpected Diagnosis. Journal of Obstetrics and Gynaecology, 27, 747-748. https://doi.org/10.1080/01443610701630682

[22] Traore, S.O., Doumbia, S., Berthé, B., Sangaré, R.T., Lefèvre, V., De Bièvre, P., Baharissoifa, M., Abdelilah, A., Abdelouahab, M., Guerin, C., Boubeker, H., Fagfouri, F., Kamdem, G., Denno, N., Timbely, O. and Mounkoro, N. (2019) Ectopic Pregnancy on Tubal Obstruction by Bilharzia Eggs at Meaux Medical Center (France). Mali Medical, 34, 51-54. 